\title{
Gendiagnostik auf Irrwegen?
}

Andreas R. Huber ${ }^{a}$,

Martin Risch ${ }^{b}$

a Prof. Dr. med., Chefredaktor «pipette - Swiss Laboratory Medicine»

b Dr. med., Präsident der SULM (Schweizerische Union für Labormedizin)

Korrespondenz:

Sekretariat SULM

SULM - Schweizerische Union

für Labormedizin

c/o MQ, Verein für medizinische Qualitätskontrolle

Universitätsspital Zürich

CH-8091 Zürich

sekretariat[at]sulm.ch
Die technischen Errungenschaften in der Labormedizin und vor allem auch in der Genanalytik erlauben, dass recht kostengünstig das Genom in sehr kurzer Zeit genauestens analysiert werden kann. Dies wird z. B. mittels Sanger-Sequenzierung, Array-Chip-Analytik und vor allem über das sogenannte Next-Generation-Sequencing möglich. Nützlich sind auch die Stabilität der DNA und die einfache Probennahme mit Abstrich von der Mundschleimhaut oder aus Blutzellen oder gar auch aus Serum oder Plasma im Falle von freier DNA. Diese Technologie hilft nun auch Scharlatanen, aus rein kommerziellem Interesse Gentests anzupreisen.

So werben Plakate in Drogerien für Gentests zur Gewichtskontrolle, die je nach Genresultat durch mehr körperliche Bewegung oder korrekte Ernährung zu erreichen sei. Es ginge nicht um Krankheiten, betont auf Nachfrage eine Verkäuferin rasch. Unserer Erklärung, dass die Aussagekraft dieser Tests etwa der- jenigen von Madame Etoile zum eigenen Horoskop entspreche, erwidert sie erstaunt, sie hätte gute Erfolge bei Klienten gehabt. Es sei eine seriöse Firma in Österreich, die diese Tests durchführe.

\section{Daten nicht geschützt ...}

Es gibt viele Anbieter von Gentests im Rahmen von Lifestyle oder Abstammungsgenealogie. Dass diese Tests aber nahe an medizinischen Diagnosen sind, beweist die Tatsache, dass die FDA der Firma «23andMe» untersagt hat, ihre Tests weiterhin anzubieten, da krankheitsrelevante und nicht nur ein-

\section{«Die Explosion von neuen Firmen} mit Trägerschaft in der schweizerischen Laborszene ist auffällig!»

fach Lifestyle-Fragen ausgetestet würden. Zudem ist der Datenschutz keineswegs garantiert. So hat aus Interesse eine Abklärung der Ahnenschaft stattgefunden. Interessanterweise stammen wir nicht von Afrikanern und auch nicht von Chinesen ab, sondern haben keltische, germanische und etwas etruskische Gene. Das erstaunte nicht wirklich. Vielmehr hat uns erstaunt, als wir der Firma telefonisch mitteilten, wir hätten das Passwort vergessen, dass dieses ohne Nachkontrolle der Identität direkt am Telefon mitgeteilt wurde. Was also mit unseren Daten geschieht, ist komplett offen.

\section{... oder Daten gut beschützt}

Noch schlimmer wird es, wenn kommerziell erfolgreiche Firmen ihre Datensätze, die wichtige Erkenntnisse z.B. über Brustkrebs enthalten, proprietär verwenden und nicht veröffentlichen. Als Scheinargument wird angegeben, man hätte Angst vor Haftpflichtprozessen und würde deshalb die Daten nicht wissenschaftlich publizieren. De facto geht es aber um den Erhalt eines Monopols. Zum Glück scheint die Vernunft auch in den USA um sich zu greifen, hat doch der oberste Gerichtshof entschieden, der Firma Myriad das Patent für die Gene BRCA1 und BRCA2 abzusprechen. Um so mehr erstaunt es, wenn ein bekannter Ständerat sich für die Auflockerung des Territorialitätsprinzips einsetzt, ohne die schweizerischen Laboratorien, die diese Analytik ebenfalls anbieten, zu kontaktieren.
CGH-Array Diagnostics: Auf Objektträgern (Arrays) sind kleine Abschnitte des menschlichen Genoms in Form von Tausenden von Oligonukleotiden aufgetragen. Durch Zugabe z. B. mit grüner Fluoreszenz markierter DNA einer Normalkontrolle und z. B. mit roter Fluoreszenz markierter DNA des Patienten, entsteht eine Hybridisierung an die entsprechenden aufgetragenen Genabschnitte. Das Fluoreszenzmuster (s. Abb.) wird dann von einem Scanner gelesen und die Information analysiert.

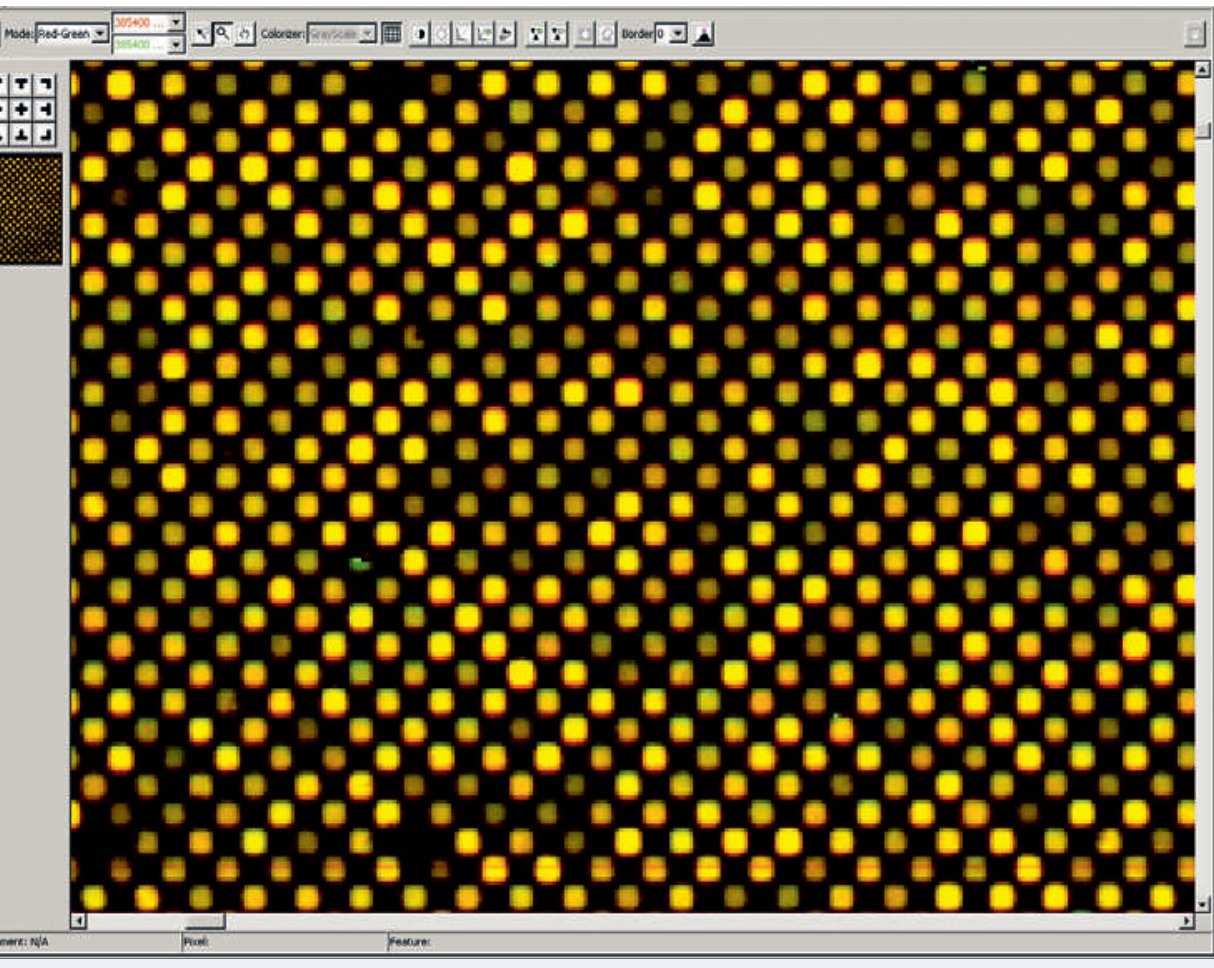


Äusserst bedenklich und gar kriminell wird es, wenn Gentests angeboten werden, um aus mütterlichem Plasma kindliche Merkmale wie Geschlecht, Augenfarbe und dergleichen vorgeburtlich auszutesten. Die Explosion von neuen Firmen mit Träger- erster Stelle durch Information der Bevölkerung über Nutzen und Schaden solcher Testresultate sowie über die Gefahren, die darin enthalten sind. Weiter über gesetzliche Massnahmen und deren konsequenter Umsetzung bei Verfehlungen. Und schliess-

\section{«Diese Technologie hilft auch Scharlatanen aus rein kommerziellem Interesse Gentests anzupreisen.»}

schaft in der schweizerischen Laborszene ist auffällig! Es scheint, als wollten sich alle vom grossen Geld eine Tranche abschneiden. Dass auch die Lebensversicherungsgesellschaften hier Morgenluft wittern und Risikokunden mit genetischen Tests ausschliessen wollen, erstaunt nicht. Es ist zu hoffen, dass die Gesellschaft diese Exzesse in den Griff bekommt. An lich durch eine verantwortungsvolle Ärzteschaft, die ihre Patienten aufklärt, instruiert und begleitet. Nur so können die vielen nicht von der Hand zu weisenden Vorteile der Gendiagnostik auch einen entsprechenden Nutzen bringen für Diagnose, Therapie, Prognose und Prävention.

\section{SULM-Tagung in Bern: Gendiagnostik}

\section{Gentests im Spannungsfeld zwischen Machbarkeit und Umsetzung}

Am 24. Juni 2014 findet die dritte SULM-Tagung in Bern statt. Sie richtet sich an Mitglieder der Verbände der SULM (Schweizerische Union für Labormedizin), Interessierte an der Labormedizin, Gesundheitsfachleute, Politiker(innen) und Medienschaffende.

\section{Risiken und Chancen}

Die Bedeutung der Gendiagnostik für die Labormedizin, das Gesundheitswesen, den rechtlichen Rahmen und die Landesgrenzen einerseits und andererseits für das Individuum und seine Angehörigen, diese Fragen werden an der SULM-Tagung aus verschiedenen Perspektiven beleuchtet. Das Potential der Genetik verlangt nach neuen Methoden der Zusammenarbeit. Daten sind flüchtiger denn je, die grosse Chance liegt in deren korrekter Anwendung und Schlussfolgerung.

In kurzen Standpunktreferaten kommen Vertreter unterschiedlicher Positionen zu Wort. So u.a. zu «Genetisches Screening - Erwägungen aus ethischer Perspektive» Frau Prof. Nikola Biller-Andorno, Direktorin und Professorin für Biomedizinische Ethik, Universität Zürich, oder zu «Genomische Medizin und Assekuranz» Prof. Thomas D. Szucs, European Center of Pharmaceutical Medicine, Basel und Präsident des Verwaltungsrats Helsana, oder zu «Das GUMG: Ein Überblick zum Vollzug» Herr Dr. Thomas Binz, Leiter Sektion Biologische Sicherheit und Humangenetik, Bundesamt für Gesundheit.

Ebenfalls vertreten sind Stimmen von Seiten der Diagnostika-Industrie, Politik und last but not least aus der Praxis. Die anschliessende Podiumsdiskussion öffnet den Raum, um die - z.T. kontroversen Fragen näher zu erläutern.

Dienstag, 24. Juni 2014, 9.15-12.45 Uhr

Kongresszentrum Allresto, Effingerstrasse 20, Bern (500m vom Bahnhofausgang West)

Die Tagungsgebühr beträgt $120 \mathrm{CHF}$ bei Voranmeldung und $180 \mathrm{CHF}$ an der Tageskasse. Fortbildungscredits sind angefragt. Anmeldungen unter: www.sulm.ch/d/aktuell/sulm-tagung

Laborszene Schweiz

Die SULM (Schweizerische Union für Labormedizin) ist Organisatorin der Tagung. Als Dachorganisation aller relevanten Fachgesellschaften mit labormedizinischer Tätigkeit thematisiert die SULM jährlich aktuelle Entwicklungen. Angesprochen sind Fachkräfte der Labormedizin, des Gesundheitswesens, Mediziner, Versicherer, Behörden, Verwaltungsräte, Health-Ökonomen, Gesundheitsdirektionen und Politiker(innen). 